\title{
Evaluation of rational use of antimicrobial agents in a Brazilian intensive care unit
}

\author{
Fabiana Xavier Cartaxo Salgado ${ }^{1,2^{*}}$, Tarquino Erastides Gavilanes Sanchez ${ }^{2}$, \\ Noriberto Barbosa da Silva ${ }^{3}$, Hildeamo Bonifácio Oliveira ${ }^{4}$, Mauro Karnikowski², \\ Margô Gomes de Oliveira Karnikowski ${ }^{1}$ \\ ${ }^{1}$ Graduate Program in Health Sciences and Technologies, Universidade de Brasília, Brasilia, Brazil; \\ *Corresponding Author: fabianacartaxo@yahoo.com.br \\ ${ }^{2}$ Brazilian Federal District Department of Health, Brasilia, Brazil \\ ${ }^{3}$ Universidade Católica de Brasília, Brasilia, Brazil \\ ${ }^{4}$ Universidade do Rio Grande do Norte, Natal, Brazil
}

Received 15 October 2013; revised 26 November 2013; accepted 15 December 2013

Copyright (c) 2014 Fabiana Xavier Cartaxo Salgado et al. This is an open access article distributed under the Creative Commons Attribution License, which permits unrestricted use, distribution, and reproduction in any medium, provided the original work is properly cited. In accordance of the Creative Commons Attribution License all Copyrights @ 2014 are reserved for SCIRP and the owner of the intellectual property Fabiana Xavier Cartaxo Salgado et al. All Copyright (C 2014 are guarded by law and by SCIRP as a guardian.

\section{ABSTRACT}

The present study sought to assess the rational use of antimicrobial agents in a Brazilian intensive care unit (ICU) and its association with antimicrobial resistance in elderly patients admitted to the unit. Results: Choice of empiric and sensitivity-guided therapy was inadequate in > $80 \%$ and $59 \%$ of cases respectively. Inadequate antimicrobial therapy, whether empiric or sensitivity-guided, was positively correlated with bacterial resistance $(r=0.316 ; p=0.001)$. Sensitivity testing revealed a $46.5 \%$ resistance rate to eight out of the ten most commonly used antibiotics. Multiple drug-resistant organisms were found in $40.8 \%$ of patients. A significant increase was observed in the number of multidrug-resistant samples between 2006/2007 and $2008(r=0.41$, $p$ $=0.006),(r=0.598, p=0.001),(r=0.688, p=0.00)$. Conclusion: We found a high rate of antibiotic misuse in the study sample. Inadequate therapy was correlated with resistance to antimicrobial agents.

\section{KEYWORDS}

Rational use of Antimicrobial Agents; Intensive Care Unit; Microbial Resistance

\section{INTRODUCTION}

Population aging is a genuinely worldwide phenome- non that has already begun to occur in Brazil [1,2]. The many complications of chronic noncommunicable diseases (CNCDs) particularly when associated with infectious disease in the elderly are determining factors of hospital admission and polypharmacy [3]. Rational use of medicines, and of antimicrobial agents in particular, is therefore a major worldwide public health concern.

Antimicrobial therapy is administered to $25 \%$ to $40 \%$ of hospital inpatients, and, in $50 \%$ of cases, is inadequate in terms of dosage, route of administration, or indication [4].

Realities such as this strengthen the notion that rational-and, therefore, adequate-use of antimicrobial agents plays an essential role in ensuring patient safety, particularly in the intensive care setting, above all because antibiotic misuse fosters bacterial resistance, making infection management more challenging and increasing the costs of health systems [5,6]. Curtailing the dissemination of antimicrobial resistance is the key objective of the World Health Organization, the PanAmerican Health Organization, and the governments of several countries, as this strategy has proved useful in reducing the morbidity and mortality of infections caused by countless pathogenic microorganisms [7].

Because they house severely ill patients (often receiving antimicrobial therapy) in a confined environment, ICUs play a significant role in the dissemination of antibiotic-resistant pathogens. ICUs are considered focal points for the implementation of effective strategies for the prevention of bacterial resistance-a concern that should be regarded by prescribers as part of routine 
management [8].

Rational use of drugs is one of the cornerstones of the Brazilian National Drug Policy [9] and the country's National Policy for Pharmaceutical Assistance [10]. However, studies conducted in Brazil have reported high rates of antimicrobial resistance, particularly in the hospital setting [11]. Furthermore, few studies conducted in the country have addressed antibiotic misuse and its consequences on microbial resistance while focusing on elderly patients in a critical care environment.

The present study sought to assess the rational use of antimicrobial agents in a Brazilian intensive care unit (ICU) and its association with antimicrobial resistance in elderly patients admitted to the unit.

\section{MATERIALS AND METHODS}

This was a three-stage, cross-sectional, patient record review study conducted at a 395-bed hospital in Brasília, Brazil, with a 10-bed mixed medical/surgical ICU.

The study sample included all patients aged 60 years or older, regardless of gender, admitted to the ICU from January to June 2006, January to June 2007, and January to June 2008, with a length of stay (LoS) of more than 24 hours, and given antimicrobial therapy. All elderly patients not receiving antibiotics were excluded from the sample.

Data on age, gender, history of invasive procedures, length of hospital stay, and clinical outcome were collected and used to construct a profile of the sample.

Assessment of the adequacy of antibiotic use was based on the concept of Rational use of drugs as proposed by the World Health Organization [12]. The guidelines set forth in the "Johns Hopkins ABX Guide" [13] were used to evaluate the criteria of antimicrobial prescription, daily dose, dosing interval, duration of treatment, and cost of treatment.

To this end, data on several antimicrobial therapy variables were collected, such as daily dose, dosage regimen (time between doses), length of antibiotic course, and cost of treatment, as well as information on the condition that prompted antimicrobial therapy. All microorganisms isolated from patient cultures were tabulated, alongside their respective antibiotic sensitivity data. Requesting microbiological tests prior to prescribing antibiotics is part of the Brazilian Consensus Guideline on the Rational Use of Antimicrobials [14,15] and was included in this study as a criterion for adequate use of antimicrobial agents.

Cost assessment was based on the acquisition cost of antimicrobial agents as purchased by the Brazilian Federal District Department of Health. The financial values provided herein have been converted to the US dollar according to its average value during 2006, 2007 and 2008, based on the exchange rate provided by the Central
Bank of Brazil. Assessment of rational cost-effectiveness in antimicrobial prescribing considered the combination of best therapeutic benefit and lowest cost, taking into account the specific clinical features of each patient, such as epidemiological history, main comorbidities, most likely site of infection, severity of clinical manifestations at the time of prescription, use of antimicrobial agents in the 30 days preceding admission, antimicrobial pharmacokinetics and pharmacodynamics, and presence of risk factors such as invasive procedures and bedsores.

Specimens for blood culture, quantitative tracheal/ bronchial aspirate culture, urine culture, and semiquantitative central venous catheter tip culture were seeded on specific media as appropriate and incubated in a MicroScan Walk-Away automated microbiology system, standardized by the National Committee for Clinical Laboratory Standards (NCCLS) [16]. Positive results were analyzed according to NCCLS criteria and subjected to antibiotic susceptibility testing (AST).

For the purposes of this study, multidrug resistance was defined as resistance to two or more classes of antibiotics in a bacterial strain intrinsically susceptible to these classes [17].

All statistical analyses were performed with the SPSS 12.5 software package (SPSS Inc., Chicago, IL). After exploratory analysis, the Kolmogorov-Smirnov test for normality was applied. Variables related to gender, age, disease, LoS, microbiological profile, antimicrobial agents administered, discharge, and death were expressed descriptively as percentages, frequencies, and mean and standard deviation. Possible correlations between multidrug resistance and LoS and antibiotic misuse and LoS were assessed with Spearman's correlation coefficient. The Kruskal-Wallis test was used to assess any differences between the number of multidrug-resistant bacteria detected in the years 2006, 2007, and 2008, whereas the Mann-Whitney $U$ was used to test for significant differences between LoS in the multidrug resistance versus no multidrug resistance groups. The significance level was set at $\mathrm{p}<0.05$.

The present study was approved by the Brazilian Federal District Department of Health Research Ethics Committee with request number 089/2007.

\section{RESULTS}

\subsection{Sample Profile}

The study sample initially comprised 117 older patients. Of these, 19 were excluded for not being prescribed antibiotics. The final sample thus included 98 patients with a mean age of $72.2 \pm 8.6$ years, 54 (55.1\%) of whom were male and 44 (44.9\%) female. Mean LoS was $19.2 \pm 15.3$ days. Forty-seven patients (47.9\%) were discharged after clinical improvement, whereas 51 
(52.1\%) died.

The infectious diseases most prevalent in the sample were pneumonia $(n=58)$, sepsis $(n=56)$, urinary tract infection $(n=12)$, and peritonitis $(n=11)$.

\subsection{Microbiological Testing}

Altogether, 376 cultures were performed, of which 152 (40.5\%) were negative, 184 (48.9\%) were positive for bacteria and 40 (10.6\%) were positive for fungi.

The microbiological profile $(79.9 \%)$ of the study sample comprised the species listed in Table 1.

\subsection{Bacterial Resistance}

Resistance to the ten most commonly used antibiotics (Table 2) in the first semester of the years 2006, 2007, and 2008 was assessed.

Table 1. Bacterial profile of the biological material under investigation.

\begin{tabular}{cc}
\hline Type of bacteria & $\mathrm{n}$ \\
\hline Gram-negative bacteria (31.6\%) & 31 \\
Pseudomonas aeruginosa & 19 \\
Acinetobacter baumannii & 18 \\
Klebsiella pneumoniae & 8 \\
Escherichia coli & 5 \\
Enterobacter cloacae & \\
Gram negative bacteria (68.4\%) & 38 \\
Staphylococcus coagulase negative & 20 \\
Staphylococcus aureus &
\end{tabular}

Table 2. Overall percentage of bacterial resistance to the antibiotics most commonly prescribed to patients in the study sample.

\begin{tabular}{|c|c|c|c|}
\hline Chemical class & Antibiotics & $\begin{array}{c}\text { Number of } \\
\text { prescriptions }\end{array}$ & $\begin{array}{c}\% \\
\text { resistance }\end{array}$ \\
\hline $\begin{array}{l}\text { Carbapenems } \\
\text { (beta-lactams) }\end{array}$ & Imipenem & 32 & 37.3 \\
\hline $\begin{array}{l}\text { Cephalosporins } \\
\text { (beta-lactams) }\end{array}$ & $\begin{array}{l}\text { Cefepime } \\
\text { (4th-gen.) }\end{array}$ & 29 & 45.9 \\
\hline Oxazolidinone & Linezolid & 29 & 0 \\
\hline $\begin{array}{l}\text { Carbapenems } \\
\text { (beta-lactams) }\end{array}$ & Meropenem & 27 & 37.3 \\
\hline Glycopeptides & Vancomycin & 25 & 0 \\
\hline $\begin{array}{c}\text { Beta-lactam }+ \\
\text { beta-lactamase inhibitor }\end{array}$ & $\begin{array}{l}\text { Piperacillin/ } \\
\text { Tazobactam }\end{array}$ & 23 & 50 \\
\hline Lincosamides & Clindamycin & 23 & 76.9 \\
\hline $\begin{array}{l}\text { Cephalosporins } \\
\text { (beta-lactams) }\end{array}$ & $\begin{array}{l}\text { Ceftriaxone } \\
\text { (3rd-gen.) }\end{array}$ & 14 & 42.3 \\
\hline $\begin{array}{c}\text { Beta-lactam }+ \\
\text { beta-lactamase inhibitor }\end{array}$ & $\begin{array}{l}\text { Ampicillin/ } \\
\text { sulbactam }\end{array}$ & 11 & 70.3 \\
\hline Fluoroquinolones & $\begin{array}{l}\text { Ciprofloxacin } \\
\text { (2nd-gen.) }\end{array}$ & 11 & 67.9 \\
\hline
\end{tabular}

Of the 651 antibiotic susceptibility tests performed, 303 (46.5\%) showed resistance to eight of the ten most commonly used antimicrobial agents. Multidrug resistance was expressed in $40.8 \%$ of microbiological examinations of the elderly, and all these patients received broad-spectrum antibiotics.

Comparison of microbiological testing results obtained during each study period showed a significant increase in the number of multidrug-resistant isolates from 2006 to 2007 and then to 2008 respectively ( $r=0.41 ; \mathrm{p}=0.006$ ), $(r=0.598 ; p=0.001),(r=0.688 ; p=0.00)$.

Comparison of mean LoS in the 40 patients in whom multidrug-resistant bacteria were cultured $(27.7 \pm 15.8$ days) to the LoS of the 58 patients in whom no multidrug resistance was detected $(14.5 \pm 12.9$ days $)$ showed that LoS was significantly increased in the first group ( $\mathrm{p}=$ 0.001 ), and that a positive correlation exists between multidrug resistance and $\operatorname{LoS}(r=0.565 ; \mathrm{p}=0.001)$.

\subsection{Adequacy of Empiric and Sensitivity-Guided Therapy}

Antimicrobial treatments $(n=286)$ prescribed to patients were empiric $70.6 \%(n=202)$ of the time and sensitivity-guided $29.4 \%(n=84)$ of the time. Only $19.8 \%$ of empiric treatments were adequate, and $41.7 \%$ of sensitivity-guided treatments. Reasons for inadequacy of empiric and sensitivity-guided treatments are shown in Table 3. It bears stressing that there was more than one reason for inadequacy per antibiotic therapy.

Overall, antimicrobial therapy was adequate in $26.2 \%$ of cases $(n=75)$, for a total cost of US\$ 58657.24, whereas inadequate antibiotic administration accounted

Table 3. Reasons for inadequacy of empiric and sensitivityguided antibiotic treatments.

\begin{tabular}{cc}
\hline Reason & $\mathbf{n}$ \\
\hline Inadequate empiric treatments (80.2\%) & 88 \\
Failure to request culture or sensitivity testing & 52 \\
Bacterial resistance to the chosen antimicrobial agent & 18 \\
Absence of a definitive diagnosis of infection & 13 \\
Use of antibiotics in fungal conditions & 7 \\
Overly long treatment duration & 3 \\
Excessive cost & 3 \\
Inappropriate dosage & 32 \\
Bacterial resistance to the chosen antimicrobial agent & 12 \\
Excessive cost & 3 \\
Inappropriate dosage & 2 \\
Overly long treatment duration & 1 \\
\hline
\end{tabular}


for $73.8 \%$ of cases $(n=211)$ for a total cost of US\$ 250677.73. Inadequate antimicrobial therapy, whether empiric or guided, was positively correlated with $\operatorname{LoS}(r=0.443 ; \mathrm{p}=0.000)$ and antimicrobial resistance $(r=0.316 ; p=0.001)$.

\section{DISCUSSION}

The elderly population admitted to the ICU in which this study was conducted matched the profile reported in previous studies. However, mean LoS and mortality rates were markedly higher, and only comparable to those reported in studies focusing exclusively on patients with sepsis and septic shock [18-20].

The range of infectious diseases leading to admission of the patients in this sample-mostly sepsis and pneumonia-accounted for the broad range of antimicrobial agents employed, with particular emphasis on the liberal administration of broad-spectrum antibiotics.

The rate of antibiotic inadequacy or misuse detected in this study, whether in empiric or sensitivity-guided therapy, was high. Administration of improper antibiotic therapy can have serious detrimental effects on patient prognosis. A study conducted by Luna et al. reported an inadequacy rate of approximately $65 \%$ for empiric therapy, with an attendant mortality of $91.2 \%$, whereas mortality in the adequate therapy group was only $37.5 \%$. Likewise, Ibrahim et al. found mortality rates of $29.9 \%$ and $11.9 \%$ in patients receiving inappropriate or appropriate antibiotic therapy respectively [21,22]. The association between proper use of antimicrobial agents and positive clinical outcomes has also been reported in studies of bacteremia and ventilator-associated pneumonia [23].

Identification of the reasons behind inadequacy of antimicrobial therapy is paramount, as it can guide interventions aimed at correcting any underlying issues.

The high rate of empiric versus sensitivity-guided therapy is due to the fact that "empiric therapy" included cases in which microbiological testing was not requested at all, whereas sensitivity-guided therapy by definition requires the availability of microbiological testing results.

Failure to request microbiological testing was the most prevalent reason for inadequacy of antimicrobial therapy. Cultures and susceptibility testing are absolutely essential to ensuring confirmation of the appropriateness of empirical therapy or redirecting therapy in a safe and effective manner so that it actually targets the causative agent of the infection [24]. Furthermore, microbiological testing provides a picture of the local microbiota and its susceptibility profile-aspects that can assist in and guide better prescribing of empiric antibiotic therapy [25]. Therefore, this valuable indicator should not be overlooked when the care setting provides conditions for microbiological analysis, as did the hospital in which the present study was conducted. Testing is particularly important in the management of ICU patients.

In this present study, many cases of inadequate empiric and guided antimicrobial therapy due to resistance to the chosen antibiotic were detected. The likelihood of correctly guessing the adequacy of the agent chosen for empiric therapy can be increased by adopting prescribing strategies based on standardized management, microbiological surveillance data, and local data on bacterial resistance. Other aspects that should be considered for adequate prescribing practices include continuously updated information on the pathophysiology of infectious diseases, an ever greater understanding of various host niches, and improved knowledge of antimicrobial pharmacokinetics and pharmacodynamics.

Concerning antibiotic misuse due to prescription of antimicrobial agents to which the causative organism is demonstrably resistant, we must stress the relevance of interpreting the results of microbiological testing correctly and assessing the actual clinical significance of these results. This can avoid inadequate prescribing and even help mitigate the consequences of bacterial selection. The selective pressure exerted by the use of antibiotics leads to the emergence of multidrug-resistant strains, compounding an increasingly worrisome public health issue [26-29].

It bears stressing that, in the event of improvement of clinical conditions, maintenance of antibiotic therapy may be justified even when susceptibility testing confirms the presence of a resistant organism.

Clinical evidence of infection-adequately documented in the patient's records — should be a prerequisite for prescription and administration of antimicrobial agents. Nevertheless, the absence of a diagnosis of infection as documented on daily patient progress notes was the third most common reason for inappropriate antibiotic therapy in this study. Administration of antibiotics to patients with systemic inflammatory response syndrome even when there is no evidence of infection is common, as is the use of antibiotics for the "treatment" of infections that require no antimicrobial therapy [30].

In the present study, to define antimicrobial therapy as "inadequate" due to cost considerations alone, we considered cases in which treatment failed to provide a combination of the best benefit associated with the lowest possible risk and cost. When the use of high-cost antimicrobial agents was justified by the patient's clinical condition, it was in no way considered inadequate for purposes of cost analysis. Nevertheless, antibiotic cost was one of the reasons for therapy being considered inadequate; furthermore, the overall cost of inadequate treatment was four times that of appropriate therapy. It is important to note that all inadequate antimicrobial ther- 
apy constitutes inadequate cost-when viewed from this standpoint, treatment costs take on an even greater financial magnitude.

Antibiotics are not usually employed in the treatment of fungal infections; however, this practice is acceptable in some cases. A common example is treatment of Pneumocystis jirovecii (carinii) pneumonia with trimethoprim/ sulfamethoxazole and primaquine in patients with AIDS [31]. None of these adequate uses were found in the present study, although antibiotics were inappropriately employed in several cases of fungal disease. The choice to use antibiotics in patients in whom a fungal etiology of infection was later confirmed may have been due to misguided clinical suspicion of bacterial infection, as therapy was empiric in the vast majority of these cases.

The prevalence of subtherapeutic dosing and excessively prolonged antimicrobial therapy detected in this study can predispose patients to adverse effects and untoward toxicity, and can also select for resistant organisms [7]. These considerations are an endorsement of the importance of guideline-based treatment as a means of preventing or minimizing prescribing errors and inappropriate therapy.

Various inadequacies in antimicrobial prescribing practice have been described in the literature, including prophylactic use of broad-spectrum antibiotics, use of antimicrobial agents in the absence of compelling clinical or microbiological evidence of infection, incorrect or unnecessary use of combination regimens, unwarranted treatment of microbial colonization, and inadequate dosage and length of antibiotic courses. All of these practices are associated with emergence of bacterial resistance [32,33].

In the present study, the prevalent microbiota was markedly resistant to the most commonly used antimicrobial agents, most of which were broad-spectrum antibiotics. This suggests that selective pressure is being exerted by the indiscriminate use of broad-spectrum agents, as has been described elsewhere in the literature $[8,34]$.

In addition, multidrug resistance is of particular concern in the more prevalent microorganisms, given the difficulty of managing and treating infections caused by these bacteria and the limited spectrum of available therapeutic options, particularly when there is resistance to carbapenems, penicillin/beta-lactamase inhibitor combinations (ampicillin/sulbactam, piperacillin/tazobactam), and third- and fourth-generation cephalosporins, as detected in this study.

Patients infected with multidrug-resistant bacteria have longer hospital stays and invariably require treatment with second- or third-line antibiotics, which may be costlier and more toxic than drugs used in the treatment of non-multidrug-resistant infections [35].
Indiscriminate use of broad-spectrum antibiotics, overly long treatment duration, and consistency of inappropriate antimicrobial therapy are all predisposing factors for the emergence of multi- and pan-resistant pathogens [29,36-38], and all were detected in this study. Multidrug resistance has become a highly relevant determining factor in the prognosis of ICU patients. The association between multidrug resistance and increased morbidity and mortality has been thoroughly documented in the literature [39-41].

In light of the high prevalence of inadequate antimicrobial therapy and of the positive correlation between antibiotic misuse and emergence of multi-resistant bacteria found in the present study, we believe there is a pressing need for all possible measures to be employed in an attempt to contain multidrug resistance. However, this is a complex issue that involves several aspects besides antimicrobial therapy-aspects that may be related to patients themselves and to the severity of their clinical condition, to hospital-wide infection control measures, to the use of invasive devices and procedures, and to the administration of immunosuppressant drugs, among other factors. Each of these aspects should be the target of specific interventions to interrupt or minimize the rise of antimicrobial resistance, particularly in the hospital setting.

However, the indiscriminate use of antimicrobial agents has been pinpointed as one of the main causes of increased antimicrobial resistance over the years, as undue use of antibiotics contrary to adequate dosage, administration, length of use, and indication recommendations favors bacterial adaptation and, subsequently, transfer of resistance genes, which are passed on to later generations of microorganisms [42]. According to Darwin, life forms that fail to adapt to the threats posed by Nature will die off, with the survivors becoming stronger and more fit to persist in the environment. The rapid reproduction of microorganisms leads to accordingly faster evolutionary change, including development of resistance [43].

The consequences of broad antibiotic use in the hospital environment can be severely detrimental to patients, to the environment, and to the institution itself [44]. Antimicrobial stewardship plays an extremely important role in managing the progression of antimicrobial resistance $[45,46]$.

Several stewardship practices can help change the current reality of antibiotic misuse: the adoption of prescriber-oriented clinical practice guidelines adapted to the local microbiota; provision of antimicrobial therapy advice by infectious disease specialists; refresher courses and continuing education on antimicrobial therapy; the operational support of a reliable, timely, and accurate microbiology service; and pharmaceutical advisory ser- 
vices seeking to implement pharmacovigilance and pharmacoeconomics practices, always in conjunction with programs aimed at restricting antibiotic use.

Studies focusing on the population aging process in Brazil are becoming the object of greater research interest, in light of the many social implications of this process and the many challenges it poses to health services. Within this context, the comorbid occurrence of infectious and chronic noncommunicable diseases is a relevant issue; as we know, older adults respond differently to these conditions and are at greater risk of unfavorable outcomes. We must therefore stress that antimicrobial agents play a key role in restoring the health of patients in this age range. Early, safe, and effective pharmacotherapy can thus define the clinical outcomes of these patients, which highlights the importance of rational use of antibiotics.

\section{REFERENCES}

[1] De Carvalho, J.A. and Garcia, R.A. (2003) The aging process in the Brazilian population: A demographic approach. Cadernos de Saúde Pública, 19, 725-733. http://dx.doi.org/10.1590/S0102-311X2003000300005

[2] Lima-Costa, M.F. and Veras, R. (2003) Aging and public health. Cadernos de Saúde Pública, 19, 700-701. http://dx.doi.org/10.1590/S0102-311X2003000300001

[3] Penteado, P., Cunico, C., Oliveira, K. and Polichuk, M. (2002) The use of drugs by the elderly. Visão Acadêmica, 3, 35-42.

[4] Correa, L. (2007) Restrição ao uso de antimicrobianos no ambiente hospitalar. Einstein: Educação Continuada em Saúde, 5, 48-52.

[5] Eickhoff, T. (1992) Antibiotics and nosocomial infections. In: Bennet, J. and Brachman, P., Eds., Hospital Infections, 3rd Edition, Brown and Company, Boston, 245-264.

[6] Neu, H. (1993) Antimicrobial agents: Role in the prevention and control of nosocomial infections. In: Wenzel, R., Ed., Prevention and Control of Nosocomial Infections, 2nd Edition, Williams \& Wilkins, Baltimore, 406-419.

[7] World Health Organization (2001) Global strategy for containment of antimicrobial resistance. Geneva. http://www.who.int/csr/resources/publications/drugresist/ WHO_CDS_CSR_DRS_2001_2_EN/en/

[8] Kollef, M.H. and Fraser, V.J. (2001) Antibiotic Resistance in the Intensive Care Unit. Annals of Internal Medicine, 134, 298-314. http://dx.doi.org/10.7326/0003-4819-134-4-200102200-0 $\underline{0014}$

[9] Brazil Ministry of Health (1998) Portaria GM no 3.916, 30 de outubro de 1998. http://bvsms.saude.gov.br/bvs/saudelegis/gm/1998/prt391 6_30_10_1998.html

[10] Brazil Ministry of Health (2004) Resolução No. 338, de 06 de maio de 2004. http://bvsms.saude.gov.br/bvs/saudelegis../cns/2004/res03

\section{8_06_05_2004.html}

[11] Struelens, M.J. (1998) The epidemiology of antimicrobial resistance in hospital acquired infections: Problems and possible solutions. The British Medical Journal, 317, 652-654. http://dx.doi.org/10.1136/bmj.317.7159.652

[12] Expert Commitee on National Drugs Policies (1995) Contribution to updating the WHO guidelines. WHO, Geneva.

[13] Unbound Medicine, Inc. (2009) The Jonh Hopkins ABX guide.

http://www.hopkinsguides.com/hopkins/ub/index/Johns Hopkins_ABX_Guide/Antibiotics

[14] Brazil, National Agency of Health Surveillance (2001) Consenso sobre o uso racional de antimicrobianos. Ministry of Health, National Agency of Health Surveillance, Brasilia.

[15] Dellinger, R.P., Levy, M.M., Carlet, J.M., et al. (2008) Surviving Sepsis Campaign: International guidelines for management of severe sepsis and septic shock: 2008. Critical Care Medicine, 36, 296-327. http://dx.doi.org/10.1097/01.CCM.0000298158.12101.41

[16] National Committee for Clinical Laboratory Standards (NCCLS) (1997) Reference method for broth dilution antifungal susceptibility testing of yeasts. Approved standard M27-A. NCCLS, Wayne.

[17] Couto, R. (2003) Bactérias multirresistentes. In: Couto, R., Pedroza, T. and Nogueira, J., Eds., Infecção Hospitalar e Outras Complicações não Infecciosas da Doença, 3rd Edition, Medsi, Rio de Janeiro, 557-588.

[18] Feijó, C.A., Bezerra, I.S., Peixoto Júnior, A.A. and Meneses, F.A. (2006) Morbidity and mortality of elderly patients admitted to an Intensive Care Unit of a University Hospital in Fortaleza. Revista Brasileira de Terapia Intensiva, 18, 263-267. http://dx.doi.org/10.1590/S0103-507X2006000300008

[19] Koury, J.C., Lacerda, H.R. and Barros Neto, A.J. (2006) Characteristics of septic patients in an intensive care unit of a tertiary private hospital from Recife, northeast of Brazil. Revista Brasileira de Terapia Intensiva, 18, 52-58. http://dx.doi.org/10.1590/S0103-507X2006000100010

[20] Machado, R.L., David, C.M., Luiz, R.R., et al. (2009) Related prognostic factors in elderly patients with severe sepsis and septic shock. Revista Brasileira de Terapia Intensiva, 21, 9-17. http://dx.doi.org/10.1590/S0103-507X2009000100002

[21] Ibrahim, E.H., Sherman, G., Ward, S., Fraser, V.J. and Kollef, M.H. (2000) The influence of inadequate antimicrobial treatment of bloodstream infections on patient outcomes in the ICU setting. Chest, 118, 146-155. http://dx.doi.org/10.1378/chest.118.1.156

[22] Luna, C.M., Vujacich, P., Niederman, M.S., et al. (1997) Impact of BAL data on the therapy and outcome of ventilator-associated pneumonia. Chest, 111, 676-685. http://dx.doi.org/10.1378/chest.111.3.676

[23] Rice, L.B. (2007) Emerging issues in the management of infections caused by multidrug-resistant gram-negative bacteria. Cleveland Clinic Journal of Medicine, 74, S12S20. http://dx.doi.org/10.3949/ccjm.74.Suppl_4.S12 
[24] Lima, A.P.., Gallani, N.R., Toledo, M.I. and Lopes, L.C. (2008) Use of Pharmacy Benefits Management (PBM) system to describe the profile of antibiotic prescription and purchase. Revista Brasileira de Ciências Farmacêuticas, 44, 215-223.

http://dx.doi.org/10.1590/S1516-93322008000200007

[25] Associação Paulista de Estudos e Controle de Infecçã Hospitalar (APECIH) (2007) Uso racional de antimicrobianos. In: Associação Paulista de Estudos $e$ Controle de Infecção Hospitalar, Câmara Brasileira do Livro, São Paulo.

[26] Fridkin, S., Lawton, R., Edwards, J.R., et al. (2002) Monitoring antimicrobial use and resistance: Comparison with a national benchmark on reducing vancomycin use and vancomycin-resistant enterococci. Emerging Infectious Diseases, 8, 702-707. http://dx.doi.org/10.3201/eid0807.010465

[27] Patrick, D.M., Marra, F., Hutchinson, J., et al. (2004) Per capita antibiotic consumption: How does a North American jurisdiction compare with Europe? Clinical Infectious Diseases, 39, 11-17. http://dx.doi.org/10.1086/420825

[28] Rüttimann, S., Keck, B., Hartmeier, C., Maetzel, A. and Bucher, H.C. (2004) Long-term antibiotic cost savings from a comprehensive intervention program in a medical department of a university-affiliated teaching hospital. Clinical Infectious Diseases, 38, 348-356. http://dx.doi.org/10.1086/380964

[29] White, R.L., Friedrich, L.V., Mihm, L.B. and Bosso, J.A. (2000) Assessment of the Relationship between antimicrobial usage and susceptibility: Differences between the hospital and specific patient-care areas. Clinical Infectious Diseases, 31, 16-23. http://dx.doi.org/10.1086/313916

[30] Penteado Filho, S. (2004) Controle de antimicrobianos: Teorias, evidências e prática. Revista Prática Hospitalar, 6, 1-7.

[31] Rachid, M. and Schechteru, M. (2005) Manual de HIVAIDS. 8th Edition, Revinter Ltda., São Paulo.

[32] Centers for Disease Control and Prevention (CDC) (2002) Campaign to prevent antimicrobial resistance in healthcare settings. 12 steps to prevent antimicrobial resistance among surgical patients.

http://www.kliinikum.ee/infektsioonikontrolliteenistus/do c/oppematerjalid/surgical.pdf

[33] Shlaes, D.M., Gerding, D.N., John Jr., J.F., et al. (1997) Society for Healthcare Epidemiology of America and Infectious Diseases Society of America Joint Committee on the Prevention of Antimicrobial Resistance: Guidelines for the prevention of antimicrobial resistance in hospitals. Clinical Infectious Diseases, 25, 584-599. http://dx.doi.org/10.1086/513766

[34] Weinstein, R.A. (2001) Controlling antimicrobial resistance in hospitals: Infection control and use of antibiotics. Emerging Infectious Diseases, 7, 188-192. http://dx.doi.org/10.3201/eid0702.700188
[35] Cartaxo Salgado, F.X., Carneiro Goncalves, J., Monteiro De Souza, C., et al. (2011) Cost of antimicrobial treatment of patients infected with multidrug-resistant organisms in the Intensive Care Unit. Medicina (Buenos Aires), 71, 531-535.

[36] Centers for Disease Control and Prevention (1992) Public health focus: surveillance, prevention, and control of nosocomial infections. Morbidity and Mortaliy Weekly Report, 41, 783-787.

[37] Gaynes, R. (1997) The impact of antimicrobial use on the emergence of antimicrobial-resistant bacteria in hospitals. Infectious Disease Clinics of North America, 11, 757-765. http://dx.doi.org/10.1016/S0891-5520(05)70388-3

[38] Jacoby, T. and Moreira, L. (2008) Associação entre consumo de antimicrobianos e multirresistência bacteriana em centro de terapia intensiva de hospital universitário brasileiro, 2004-2006. Master’s Thesis, Federal University of Rio Grande do Sul, Porto Alegre.

[39] Chow, J.W., Fine, M.J., Shlaes, D.M., et al. (1991) Enterobacter bacteremia: Clinical features and emergence of antibiotic resistance during therapy. Annuals of Internal Medicine, 115, 585-590. http://dx.doi.org/10.7326/0003-4819-115-8-585

[40] Goldmann, D.A., Weinstein, R.A., Wenzel, R.P., et al. (1996) Strategies to prevent and control the emergence and spread of antimicrobial-resistant microorganisms in hospitals. A challenge to hospital leadership. The Journal of the American Medical Association, 275, 234-240. http://dx.doi.org/10.1001/jama.1996.03530270074035

[41] Johnson, M.P. and Ramphal, R. (1990) Beta-lactamresistant Enterobacter bacteremia in febrile neutropenic patients receiving monotherapy. Jorunal of Infecious Diseases, 162, 981-983.

http://dx.doi.org/10.1093/infdis/162.4.981

[42] Worley, H. (2006) La resistencia a los antimicrobianos pone en riesgo el avance médico. http://www.prb.org/SpanishContent/2006/LaResistenciaal osAntimicrobianosPoneenRiesgoelAvanceMedico.aspx

[43] Quadros, C. (2004) Estratégias para controle de resistência antimicrobiana em unidades de terapia intensiva. MBA Thesis, University City of São Paulo, São Paulo.

[44] Eickhoff, T. (1998) Antibiotics and nosocomial infections. In: Bennet, J. and Brachman, P., Eds. Hospital Infections, Lippincott-Raven, Philadelphia, 201-214.

[45] Dellit, T.H., Owens, R.C., McGowan, J.E., et al. (2007) Infectious Diseases Society of America and the Society for Healthcare Epidemiology of America Guidelines for developing an institutional program to enhance antimicrobial stewardship. Clinical Infectious Diseases, 44, 159-177. http://dx.doi.org/10.1086/510393

[46] Centers for Disease Control and Prevention (CDC) (2001) A public health action plan to combat antimicrobial resistance. Part I. Domestic issues. http://www.cdc.gov/drugresistance/actionplan/index.htm 